\title{
Rethinking Urbanization: A Transit-Information-Communication -Technology-Oriented Development Path for the Developing Countries and Post-Industrial Towns
}

\author{
Schuman Lam*, Heng Li iD, Ann T.W. Yu \\ Department of Building and Real Estate, The Hong Kong Polytechnic University, Block Z, \\ Hung Hom, Kowloon, Hong Kong
}

Received 24 November 2020/Revised 21 March 2021/Accepted 28 March 2021/Published 25 April 2021

\begin{abstract}
This study explores a new path of urbanization to enhance the conventional economy-led urban development practice by conducting an urban quality of life (Uqol) survey. It analyzes the Uqol evaluation gap caused by demographic attributes between developing countries, developed countries, and post-industrial town. We adopted a mixed-methods research design, including a literature review and an Uqol survey, to suggest the transit-oriented-development (TOD) and information-communication-technology (ICT) based urban-rural development concept. The finding indicates a disparity of Uqol mean score rankings among the developing countries, developed countries, and the marginalized post-industrial town. It highlights the health, transportation, socio-economic, and technological development in the developing countries strongly desired. Furthermore, Kruskal-Wallis H-test and Mann-Whitney U-test results show significant differences in economy, technology-ICT, smart living, and lifestyle within education, profession, age, and country groups. It clarifies that the well-being gap is shaped by demography and exhibited geographically, which implies TOD-ICT advancement can break down geographical barriers for achieving sustainable growth in remote areas. Supported by the planetary urbanization theory, the human-technology-driven urban development process would facilitate the maturity and implementation of the proposed TODICT-based urban-ruralism (UxR) concept for enhancing the future global urbanization process.
\end{abstract}

Keywords : Human and Social Geography; Information-Communication-Technology; Urban Policymaking; Transit-Oriented-Development; Urban Quality of Life

\section{Introduction}

Nowadays, pressing global urban issues caused by overdevelopment appeals to practical solutions. Unsustainable urban development policy driven by industrialization and adopted by the developed countries has been proved to be the due cause (Club of Rome, 2018). Economy-led industrialization and urbanization have been reshaping our urban landscape in both the developed and the developing countries of the world (Unicef, 2020)

*Corresponding author.

Email address : 14900559r@ connect.polyu.hk (Schuman Lam) 
with an impressive record of economic growth while causing damage to other aspects of urban quality of life (Uqol) and the ecological environment (Dong et al., 2016).

Regarding the urban problems left from industrialization we are all facing, world leaders and policymakers must rethink their urban development roadmap to improve their citizens' livelihoods while preserving enough resources to accommodate the next generations' needs. In developing countries, where most of their bare landscapes are yet for development, the kind of sustainable development path adopted by the developing countries in Asia and Africa is extremely critical to the fight against climate change and degradation of living quality. Thus, the ways of life preferences of people from these regions become the primary study for policymakers and this study's vital task.

Climate change and a series of urban problems are the adversaries and predicament affecting people's well-being. For a long time, every government has tried to tackle the problems by designing and implementing the needed urban policies. Unfortunately, their effort has not been paid off because the rhetoric approach lacks flexibility and operability. Although the general definition of Uqol would be pure rhetoric to understand, its implication on government policies considering individual needs must be evaluated and communicated among the stakeholders effectively because the Uqol evaluation result can inform policymakers and planners the essential information to build and manage the city in a sustainable manner (Marans, 2015). The relationship between quality of life evaluation, industrialization-urbanization, and sustainable urban development (SUD) determines Uqol survey location: developing countries, developed countries, and developed post-industrial Mirafiori town.

Quality of Life (QOL) is a critical topic in urban development due to its function in monitoring public policies as a useful tool (Rezvani et al., 2013). However, its multi-faceted and quite inter-disciplinary subjective nature makes it challenging to understand and evaluate the real meaning comprehensively and precisely for mutual communication and cooperation among the stakeholders. The study of QOL started in the USA in the 30s. In the social indicator movement period, Chicago School began to study QOL by mixing social science and geography (Mikkelsen \& Di Nucci, 2015).Then the realization of objective indicators as the measurement of QOL was in its maturity in the 60s, which was expanded to include the disciplines of politics, economics, geography, planning, architecture, environmental studies, psychology, medicine, education, and others (Mikkelsen \& Di Nucci, 2015), but not much in the field of sustainable urban development (SUD). In this period, a top-down policy-driven approach for studying and evaluating QOL centered around economic development was adopted: objective indicators like GDP, employment data, mortality and morbidity rate, and 
crime rates have been used to evaluate QOL because living conditions and standard of living to the implementation of economic and social policies were the new approaches to study QOL (Land et al., 2012). Between the 1970s and 1980s, QOL became a multi-dimensional concept, including other dimensions of human life (Rodriguez, 2015).

In the past 20 years, a resurgence of the QOL study movement was driven by the research community (academic and private), city government, and world institutions (Marans \& Stimson, 2011), especially by public policy, urban governance, planning, and management, and sustainable development for enhancing Uqol (McCrea et al., 2006). Many of the studies were nation or city ranking reports mainly driven by economic growth to serve the capital-led development trajectory. In the 1990s-2010s, there was the advocacy of establishing a more comprehensive mechanism (top-down policy-driven and bottom-up subjective-well-beingsurvey - SWBS) for studying QOL by (Diener, 1995; Marans \& Kweon, 2011). Still, the research market on the direct link of QOL and SUD is missing. More research on (QOL + SUD = Uqol) in both qualitative and quantitative studies should be encouraged, while SUD has been well advocated by the world institutions such as United Nations (UN) and World Commission on Environment and Development (WCED, 1987) because SUD aims for uplifting QOL. Until the 2010s onward, there were different types of QOL ranking reports attending to evaluate people's well-being and livelihoods in the context of mobility, sustainability, happiness, social progress, and technology.

The Uqol evaluation criteria refer to them as the base to develop the 11 Uqol indicators (health, environment, mobility, governance, human capital, social, economy, technology-ICT, culture, smart living, and lifestyle) to examine the Uqol evaluation gap shaped by demographic and geographical attributes. As per the World Health Organization (Dan Bar-On, 1995), quality of life (QOL) is individual perceptions related to their position based on the character of cultural background and values in life and life goals. Their value systems have been influenced by the demographic and geographical background of the urban environment they lived in (Campbell, 1976; Marans \& Stimson, 2011; Potter et al., 2012; Murgaš \& Klobučník, 2018). Wilson \& Jonas (2018) described that urbanization is the interface to glue the multi-layers of ways of life, from the internal thoughts to the external political, social, economic, and physical morphologies. This notion expresses that urbanization is not a form and can be interpreted as a human development process or movement, interpreted by human geography. Thus, the debating planetary urbanization theory was adopted as the theoretical base to start the exploratory study. In such a notion, we argued that there are evaluation gaps between the developing countries, developed countries, and developed post-industrial towns; thus, the conventional economy-led urbanization 
roadmap needs to be updated for securing the sustainable growth of our planet (The Sustainability Development Goals aim to fight poverty and hunger, confront the climate crisis, achieve gender equality, and much more).

The study was motivated by the Sustainable Development Goals (United Nations, 2020) advocated by the United Nations. The 2-degree Celsius threshold line set by the previous Paris Agreement (UNFCCC, 2016) in fighting climate change has not been materialized to deepen the fault further, rapid industrialization and urbanization in Asia and Africa where the developing countries are playing catch up in economic development. The performance of environmental sustainability depends on the people's engagement, particularly at the local level; mutual understanding and cooperation are needed to achieve the climate change goal set by the Paris Agreement. As problems accumulate faster than the solution, the evolutionary transition to a new urban development paradigm becomes necessary. We believed that a new study approach, systems, and tools enabling the transformation from a synergistic one should be explored.

Urbanization is a dynamic-adaptive-complex system bred in constant mutation with unique local characteristics, not a simple generic organism. Since the industrial period, urbanism is being reproduced and remade worldwide according to which trajectory has been laid by capitalism (Brenner \& Schmid, 2015). In the digital period, should we keep on walking along the same development path adopted by the developed countries? To locate a new future sustainable urban development path, we need to understand the composition of perceived Uqol subject to the roles of demographic and geographical groups and then envisage the feasible route to reach the sustainable development goals. Given the previous literature review regarding sustainable urban development, quality of life, and planetary urbanization, the mismatch of the human condition (value/demand) and the offering/supply of global urbanism require local investigation to redefine and refine the claim by Brenner \& Schmid (2015), which the evaluation of Uqol can contribute to the task. Thus, we conducted an Uqol survey to analyze and interrogate the hypothesis of the "urban quality of life (Uqol) evaluation gap is caused by subjective demographic and geographical attributes in shaping the urban landscape." based on the debatable planetary urbanization theory.

For a long time, GDP has been the de facto quality of life indicator for evaluating Uqol in terms of economic growth alone due to market need. However, a few researches focused on studying the interrelationship of SUD and QOL and their undeniable role in urban policymaking. The gap between the subjective well-being and sustainable requests must be compromised through implementing a different urban development path addressing Uqol beyond economic growth. This research intends to explore a new human-oriented 
development concept to merge the well-being gaps between the developed and developing countries for reaching global sustainability.

The objectives of this research are: (1) to present and discuss the Uqol evaluation gap between the concerned geographical domains; (2) to locate the independent groups contributing to the Uqol evaluation by examining the relationship of demographic attributes to geographical domains in ranking the well-being indicators; (3) to predict future sustainable urban development needs by analyzing the Uqol mean score significant differences among the different categories of education, profession, age, developing countries, and developed countries. By comparing and discussing the relationship of urban development and various aspects of urban life requests at the community and country levels, the study provides the rationale to develop a novel TOD-ICT-based urban-ruralism (UxR) development concept for merging the well-being gap between the urban and rural areas and the developing and developed countries.

\section{Methods}

\subsection{Research Design}

A mixed-methods research design started with a literature review to state the motivation, evaluation gap, the theory-based argument, and the objectives for fulfilling the overall aim, validated by the data collected from an Uqol survey. Convenient sampling was conducted via online and offline channels for six months in 2018-19. IBM SPSS Statistics 20 English version software was hired to run the raw data collected from the survey. The mean score (MS) test and the non-parametric Kruskal-Wallis H-test and Mann-Whitney U test produced the quantitative results. We conducted Descriptive Statistics, Cronbach's Alpha reliability test, normality test, non-parametric MS tests to generate the scientific results. First, the Cronbach's alpha reliability test (Likert scale bigger than 0.7) justified that the chosen scale was suitable, the data collection instrument was strongly reliable, and the responses were consistent with the survey to reduce the bias of results (Shen et al., 2012; Sullivan \& Artino, 2013; Gokdemir \& Dumludag, 2011). The scientific results will then be presented with a mean score test and non-parametric Kruskal-Wallis H-test, and MannWhitney $U$ test in the results and discussion section. The techniques for running the data have been practiced and illustrated (Kingsford \& Chan, 2019).

\subsection{Demographic and Geographical Profile}

The sample total is 358 (64\% developed countries and 36\% developing countries) from 47 countries (Figure 1). We analyzed data from the two geographical domains because they represent different urban development stages; the 'developed countries' were developed 
with the economy-led development policies. The 'developing countries' are ready for progressive development whose future development path is critical for tackling climate change issues. Female respondents (56\%) are more than male respondents (44\%). Age 2635 occupies the highest portion (38\%) of the sample, followed by age 16-25 (20\%), 36-45 $(17 \%), 46-55(14 \%)$, and $56+(11 \%) .43 \%$ are postgraduate, $29 \%$ are undergraduate, and $28 \%$ below undergraduate. In the professional group, 36\% are students, $49 \%$ are employed, and $15 \%$ are either retired or unemployed. The sample profile reflects a young diversified, and well-educated group of representation, which would serve as the applicable sample to advise the future sustainable urban development requests.

Percentage frequency

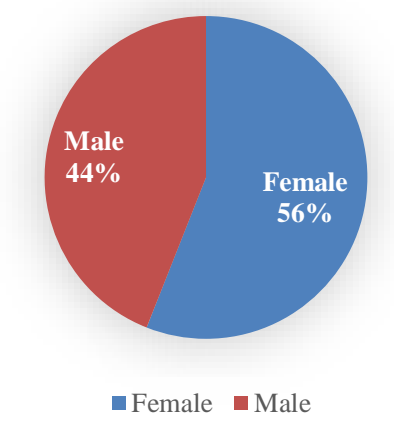

Percentage frequency (education)

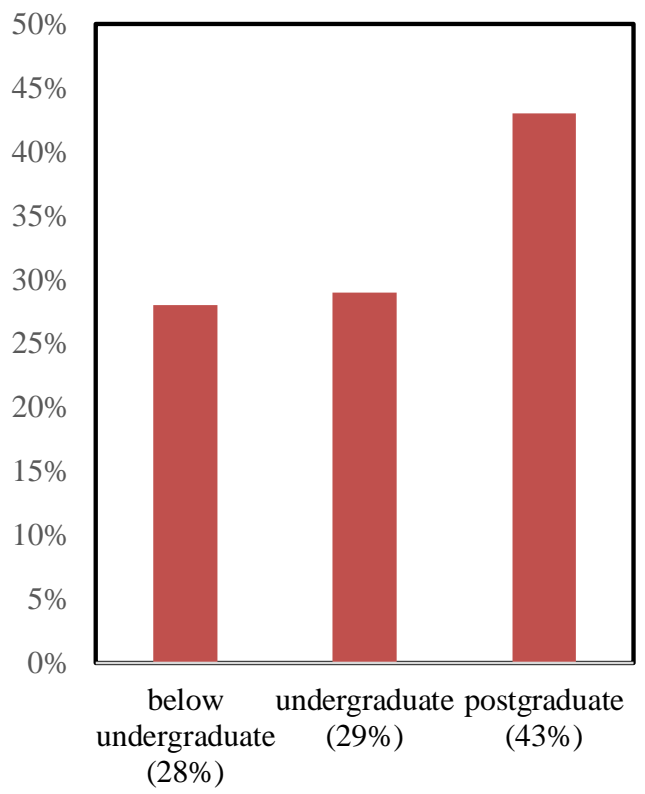

Percentage frequency (age)

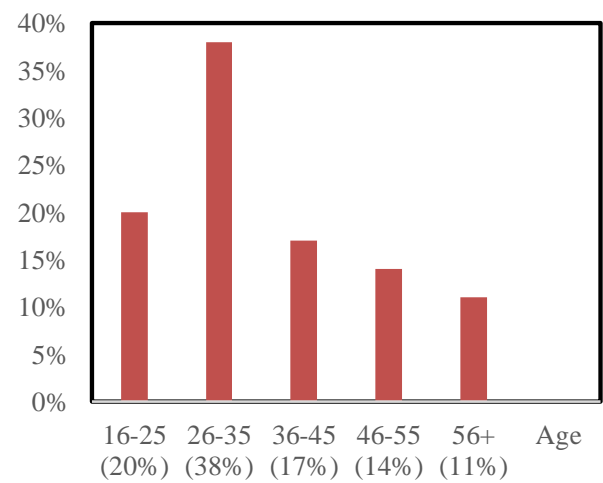

Percentage frequency (profession)

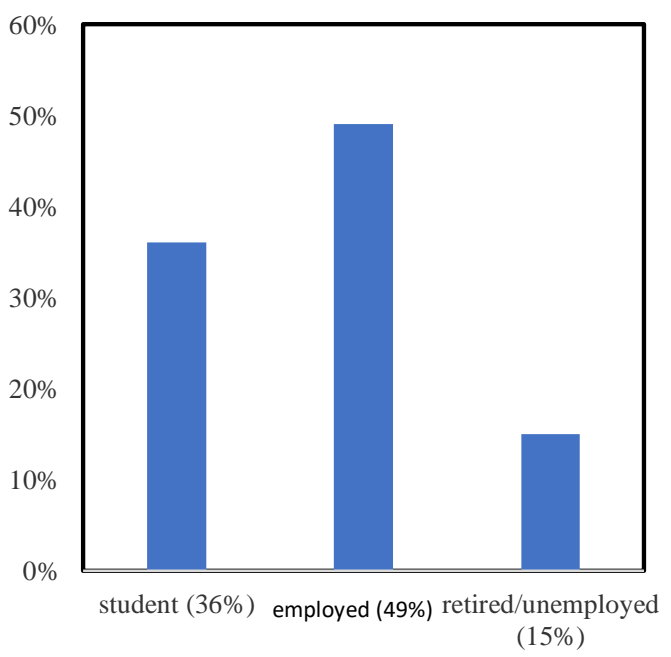

Figure 1. Sample demographic profile 


\section{Results and Discussion}

We discuss the results in three parts. Several critical issues are highlighted by comparing and analyzing the mean score (MS) ranking results of developing countries, developed countries, and developed Mirafiroi community (a post-industrial town in Italy was chosen to represent the historical drawback left by industrialization) and significant differences in age, education, profession, and country groups. This section illustrates the perceived well-being evaluation gap between developed countries, developing countries (a proxy of urban and rural well-being representation). It reveals a critical point of demographic groups shaping the loading pattern of geographical representation and restating the relationship of the independent demography to the dependent geography. The finding allows the further exploration of the hybrid urban-ruralism development concept.

\subsection{Macro: Comparing Uqol Mean Rankings by Geographical Domains}

The composition of 11 Uqol dimensions was extracted from the relevant world Quality of Life indices (CIMI, 2018; GPCI, 2018; SCI, 2018; SCMI, 2017; MQCR, 2018; SPI, 2018) guided by the global concept of sustainability development. The 11 identified Uqol criteria had been discussed and tested by a professional panel composed of Professors / Scholars and Ph.D. Students are the experts in sustainable urban planning, sociology, environmental, architecture, and design engineering from the Interuniversity Department of Regional and Urban Studies and Planning in the Politecnico di Torino, Italy twice. It was then verified by a mean score test at the threshold of $\mu \geq 1.5$ with a respondent rate over $90 \%$ and p-value: $0.000<0.005$. The respondents were asked to rank the 11 Uqol indicators in a 3point Likert scale set.

Table 1. Comparing mean ranking of the $11 \mathrm{Uqol}$ indicators

\begin{tabular}{|c|c|c|c|c|c|c|c|c|c|c|c|c|}
\hline \multirow[t]{2}{*}{ Dimensions } & \multicolumn{4}{|c|}{ Mirafiori $^{2}$} & \multicolumn{4}{|c|}{ Developed Countries ${ }^{3}$} & \multicolumn{4}{|c|}{ Developing Countries ${ }^{4}$} \\
\hline & $\mathrm{Rm}$ & Mean & SD & Rank & $\mathrm{R} 1$ & Mean & $\mathrm{SD}$ & Rank & $\mathrm{R} 2$ & Mean & SD & Rank \\
\hline Health & 98.0 & 2.91 & .353 & 1 & 98.7 & 2.77 & .543 & 1 & 98.5 & 2.76 & .558 & 1 \\
\hline Environment & 96.0 & 2.65 & .578 & 2 & 97.4 & 2.57 & .632 & 2 & 96.9 & 2.56 & .614 & 6 \\
\hline Mobility & 97.0 & 2.65 & .520 & 2 & 98.2 & 2.50 & .591 & 4 & 96.9 & 2.62 & .578 & 2 \\
\hline Governance & 95.0 & 2.53 & .664 & 4 & 96.1 & 2.52 & .652 & 3 & 95.4 & 2.57 & .587 & 5 \\
\hline Continued & & & & & & & & & & & & \\
\hline
\end{tabular}




\begin{tabular}{|c|c|c|c|c|c|c|c|c|c|c|c|c|}
\hline \multirow[t]{2}{*}{ Dimensions } & \multicolumn{4}{|c|}{ Mirafiori $^{2}$} & \multicolumn{4}{|c|}{ Developed Countries ${ }^{3}$} & \multicolumn{4}{|c|}{ Developing Countries ${ }^{4}$} \\
\hline & $\mathrm{Rm}$ & Mean & SD & Rank & $\mathrm{R} 1$ & Mean & $\mathrm{SD}$ & Rank & $\mathrm{R} 2$ & Mean & SD & Rank \\
\hline $\begin{array}{l}\text { Human } \\
\text { Capital }\end{array}$ & 93.1 & 2.52 & .668 & 5 & 96.1 & 2.50 & .666 & 4 & 94.6 & 2.59 & .572 & 4 \\
\hline Social & 97.0 & 2.47 & .692 & 6 & 99.1 & 2.46 & .687 & 6 & 93.1 & 2.60 & .598 & 3 \\
\hline Economy & 95.0 & 2.04 & .807 & 10 & 96.5 & 2.19 & .740 & 8 & 95.4 & 2.56 & .629 & 6 \\
\hline $\begin{array}{l}\text { Technology } \\
\text { ICT }\end{array}$ & 96.0 & 2.12 & .832 & 8 & 95.6 & 2.13 & .722 & 9 & 93.1 & 2.45 & .658 & 8 \\
\hline Culture & 98.0 & 2.23 & .750 & 7 & 96.9 & 2.21 & .710 & 7 & 93.1 & 2.17 & .691 & 10 \\
\hline Smart Living & 93.1 & 2.05 & .821 & 9 & 94.7 & 1.99 & .759 & 10 & 93.8 & 2.22 & .662 & 9 \\
\hline Lifestyle & 93.1 & 1.89 & .782 & 11 & 95.2 & 1.96 & .763 & 11 & 93.8 & 2.17 & .712 & 10 \\
\hline
\end{tabular}

Note $: \mathrm{Rm}=$ respondent rate from Mirafiori; Sample size of $\mathrm{Rm}=101 ; \mathrm{R} 1=$ respondent rate from the developed countries; Sample size of R1 = 228; R2 = respondent rate from the developing countries; Sample size of R2 = 130. Total sample size: $\mathrm{R} 1+\mathrm{R} 2=358$; Reliability test of the 11 dimensions: Cronbach's Alpha (all countries = .845) $($ developed countries $=.848)($ developing countries $=.825)$. Statistical significance: 0.05 ; Mean score ranking test: $\mu \geq 1.5 \mathrm{p}$-value: $0.000<0.05$ for total sample size. $2=$ Mirafiori is a periphery post-industrial town situated in the capital city of Piedmont, Turin. Turin is Italy's third-largest economic centre after Milan and Rome and situated in the southern part of the city is a typical marginal motor workers town awaiting revitalization. 3=Developed countries: Australia, Austria, Belgium, Bulgaria, Canada, Croatia, Czechia, Finland, France, Germany, Greece, Ireland, Italy, Japan, Latvia, Netherlands, Poland, Republic of Korea, Romania, Spain, Sweden, UK, USA. ${ }^{4}$ Developing countries: Argentina, Azerbaijan, Bangladeshi, Benin, Brazil, China, Colombia, Egypt, Ethiopia, Ghana, India, Indonesia, Iran, Kazakhstan, Lebanon, Malaysia, Mexico, Morocco, Nigeria, Pakistan, Philippines, Russia, South Africa, Sri Lanka.

As expected from Table 1, the developed Mirafiori community has a similar ranking result as the developed countries, except for mobility and economy, a reflection of well-being gap can exist in the multi-scalar urban system (nation-city-town-village). Overall MS scores are $2.48,2.35$, and 2.37 out of 3 for the developing countries, developed countries, and the developed Mirafiori community, which can be interpreted as people from the 'developing countries' is more driven than from the 'developed countries' because the former lives less off than the latter. Although the relevantly higher MS score garnered by the developing countries over the other two domains might signal that the macro Uqol evaluation is geographically divided into the developed and developing regions, the below combo chart reiterates the well-being gap between the three geographical groups while showing disparities and similarities in the groups. The findings will be examined with a micro illustration. 


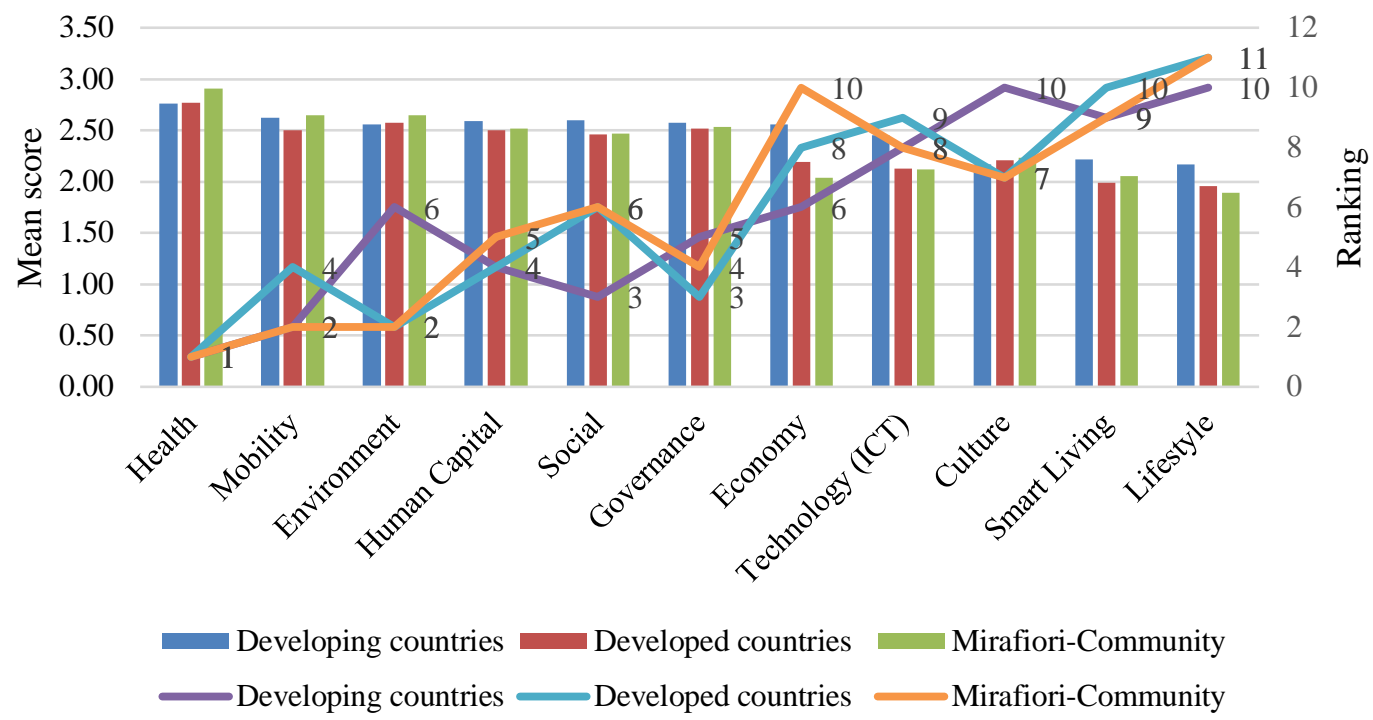

Figure 2. Combo chart of the mean score and ranking lines of the three geographical domains (developing countries, developed countries, and developed Mirafiori community)

Figure 2 is a visual presentation of (Table 1) for easy understanding. The top-ranking of health unanimously signifies that urban development should be human-oriented, focusing on healthy social-economic-environmental development as per the need-based survey. We analyzed and discussed the results from three perspectives: (1) developing countries vs. developed countries, (2) developing countries vs. developed Mirafiori community, and (3) MS ranking comparison of the three geographical domains.

First, a greater Uqol MS ranking division exists between the developing and developed countries. The lower the ranking number shows the stronger the well-being criteria demanded by the respondents. The developing countries perceived the environment, governance, and culture $\left(6^{\text {th }}, 5^{\text {th }}\right.$ and $\left.10^{\text {th }}\right)$ as less critical than developed countries $\left(2^{\text {nd }}, 3^{\text {rd }}\right.$ and $\left.7^{\text {th }}\right)$. The developing countries ranked mobility, social and economy criteria $\left(2^{\text {nd }}, 3^{\text {rd }}\right.$ and $\left.6^{\text {th }}\right)$ relatively stronger than the developed countries $\left(4^{\text {th }}, 6^{\text {th }}\right.$ and $\left.8^{\text {th }}\right)$. It indicates that developing countries valued mobility, economic and social development over the developed countries (Ali \& Al Nsairat, 2009). Worth noting that developing countries have a similar MS of environment (2.56) as the developing countries (2.57), possibly because it has been recognized that environmental quality affects personal health. Second, the developing countries and the developed Mirafiori community ranked mobility at $2^{\text {nd }}$ place deviated from the developed countries $4^{\text {th }}$ place. It shows that transportation is lacking in the developing and the developed post-industrial town; therefore, the urban development stage might not be the factor for causing the well-being gap when we factor in geographical scale and time would 
neutralize specific well-being gaps between the two groups. The implication will be investigated in future research because it is not the primary concern of this paper. Third, the similar ranking section comprises human capital, technology-ICT, smart living, and lifestyle, proving that human-technological-driven as the conventional well-being needs in the digital age.

Noticeably, the Uqol evaluation gap exists between the developing countries and developed countries. The developing countries value socio-economic development relevantly stronger than the developed regions. Inside the country group, there are overlapping wellbeing needs by the developing countries and the developed post-industrial town. Residents from the once-prosperous motor-town Mirafiori want good health and a transport-led habitat where nature, culture, and social activities can flourish with a well-balanced urbanized style. Its MS ranking result demonstrates a unique socio-spatial developed post-industrial town. Characterized by the local context, constraints, and demands, which originated and built along with the economic-driven agenda, it has since evolved into its color and form to differentiate itself from developed countries. The economy's ranking is surprisingly low $\left(10^{\text {th }}\right.$ place out of 11 indicators) from the post-industrial community; $8^{\text {th }}$ place in the developed countries and $6^{\text {th }}$ place in the developing countries. It demonstrates that GDP as the sole indicator to evaluate people's well-being needs is not realistic. The economy-led development path needs a facelift to meet the market needs while securing a sustainable future.

\subsection{Micro: Comparing Mean Score by Demographic Groups}

This section illustrates the pattern loading of mean score (MS) disparities by gender, education, profession, and age groups, which provides an in-depth analysis of the macro MS ranking results by geographical domains. We utilized the MS ranking report of sample demography (Table 2) to examine the relationship of demographical attributes to the geographical groups while removing the systematic and random errors principally.

Table 2. Mean score reports of sample demography

\begin{tabular}{|c|c|c|c|c|c|c|c|c|c|c|c|}
\hline & 1 & 2 & 3 & 4 & 5 & 6 & 7 & 8 & 9 & 10 & 11 \\
\hline Gender: Female & 2.76 & 2.56 & 2.53 & 2.60 & 2.52 & 2.51 & 2.34 & 2.21 & 2.13 & 2.03 & 2.05 \\
\hline Male & 2.84 & 2.61 & 2.63 & 2.50 & 2.60 & 2.57 & 2.39 & 2.32 & 2.28 & 2.14 & 2.01 \\
\hline \multirow[t]{3}{*}{ Education: } & 2.87 & 2.69 & 2.58 & 2.62 & 2.58 & 2.45 & 2.06 & 2.07 & 2.24 & 1.98 & 1.81 \\
\hline & 2.76 & 2.48 & 2.49 & 2.58 & 2.47 & 2.51 & 2.45 & 2.26 & 2.22 & 2.17 & 2.13 \\
\hline & 2.77 & 2.58 & 2.61 & 2.50 & 2.59 & 2.60 & 2.49 & 2.37 & 2.14 & 2.08 & 2.11 \\
\hline Continued & & & & & & & & & & & \\
\hline
\end{tabular}




\begin{tabular}{|c|c|c|c|c|c|c|c|c|c|c|c|c|}
\hline & & 1 & 2 & 3 & 4 & 5 & 6 & 7 & 8 & 9 & 10 & 11 \\
\hline \multicolumn{2}{|c|}{ Profession: 1} & 2.86 & 2.63 & 2.65 & 2.55 & 2.60 & 2.63 & 2.50 & 2.45 & 2.24 & 2.18 & 2.19 \\
\hline & 2 & 2.71 & 2.53 & 2.50 & 2.55 & 2.54 & 2.48 & 2.37 & 2.26 & 2.21 & 2.10 & 2.03 \\
\hline & 3 & 2.93 & 2.64 & 2.62 & 2.56 & 2.51 & 2.47 & 1.96 & 1.78 & 2.02 & 1.73 & 1.67 \\
\hline \multirow[t]{5}{*}{ Age: } & $16-25$ & 2.89 & 2.64 & 2.57 & 2.66 & 2.62 & 2.61 & 2.38 & 2.30 & 2.21 & 2.07 & 2.16 \\
\hline & $26-35$ & 2.77 & 2.55 & 2.63 & 2.51 & 2.52 & 2.55 & 2.43 & 2.41 & 2.23 & 2.17 & 2.12 \\
\hline & $36-45$ & 2.81 & 2.63 & 2.48 & 2.59 & 2.59 & 2.54 & 2.46 & 2.26 & 2.24 & 2.11 & 2.09 \\
\hline & $46-55$ & 2.67 & 2.58 & 2.47 & 2.56 & 2.58 & 2.58 & 2.51 & 2.29 & 2.31 & 2.16 & 1.98 \\
\hline & $56+$ & 2.87 & 2.55 & 2.65 & 2.45 & 2.45 & 2.26 & 1.65 & 1.52 & 1.74 & 1.55 & 1.45 \\
\hline
\end{tabular}

Note : Uqol dimensions: 1=Health; 2=Environment; 3=Mobility; 4=Governance; 5=Human Capital; 6=Social; 7=Economy; 8=Technology-ICT; 9=Culture; 10=Smart Living; 11=Lifestyle Education: 1=Below undergraduate; 2=Undergraduate; 3=Postgraduate Profession: 1=Student; 2=Employed; 3=Retired / Unemployed

By referring to the MS results listed in Table 1 and Table 2, we generated an array of radar diagrams (Figure 3) to illustrate the loading pattern of Uqol evaluation for discussion. In general, all groups perceived health, environment, mobility, governance, and human capital with similar MS. However, a greater disparity in the economy, technology-ICT, culture, smart living, and lifestyle was indicated. The 'below undergraduate' perceived the importance of the economy, technology-ICT, and lifestyle relatively less significant than the 'above undergraduate' in the education group, which needs further investigation to locate the underlying factors. In the professional group, the 'retired-unemployed' perceived the value of the social, economy, technology-ICT, culture, smart living, and lifestyle relatively less significant than the 'students' and the 'employed'. Age 56+ perceived social, economy, technology-ICT, culture, smart living, and lifestyle are less critical than the younger groups in the age group.It is mainly due to retired aging respondents being less active in engaging in socio-economic activities and technology-driven lifestyles.
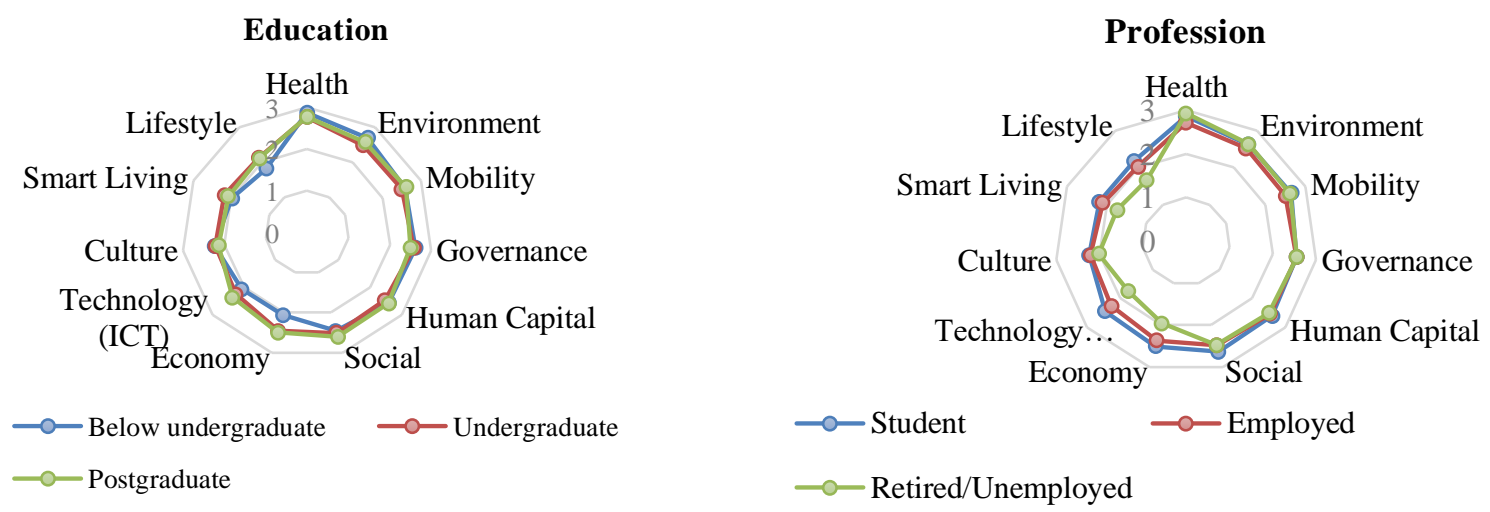

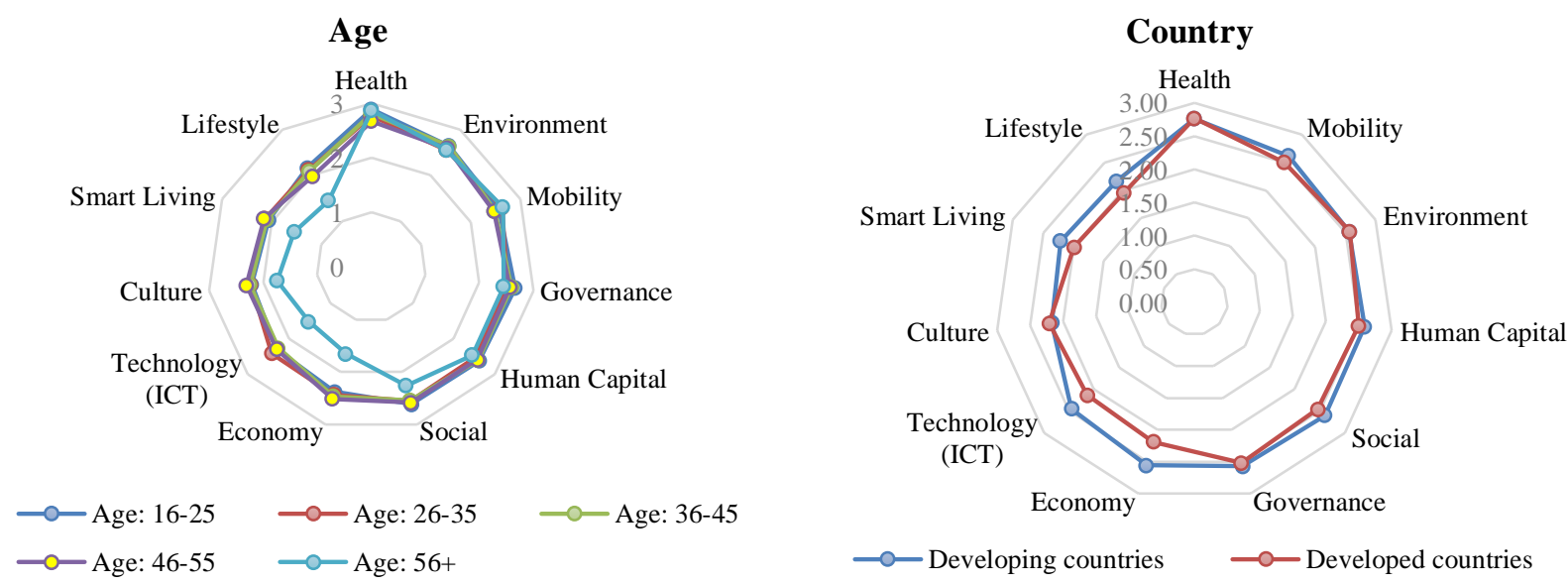

Figure 3. Mean score disparities of different demographic and geographical groups

In Figure 3, the micro demographic groups' loading pattern is consistent with the macro country groups, which might state that the independent demographic variables affect the dependent geographical variables. Based on this analysis, we revise the original hypothesis 'urban quality of life (Uqol) evaluation gap is caused by demographic and geographical attributes in shaping the urban landscape' into 'Uqol evaluation gap is caused by demographic and exhibited geographically for shaping the urban landscape. 'By studying demographic Uqol evaluation, we can locate the evaluation gap factors for informing future urban development. However, to predict the future urban development beyond the sample representation, we need to conduct the Kruskal Wallis H-Test and Mann-Whitney U Test to identify the statistically significant differences of Uqol demands to estimate the urban supply for reaching the equilibrium state of development.

\subsection{Determining Uqol Significant Differences Demographically and Geographically}

Table 3 shows basically no perceived value of significant differences in the health, environment, mobility, governance, human capital, and culture criteria meaning that the governments need to distribute resources to accommodate the five well-being requests in their urban policies. Kruskal-Wallis H-test displays a significant variation in the social, economy, technology-ICT, smart living, and lifestyle among the demographic groups. MannWhitney $U$ test highlights significant differences between developing and developed countries in the economy, technology-ICT, smart living, and lifestyle. The significant differences criteria inform policymakers to conduct an empirical study to investigate the latent reasons. 
Table 3. Kruskal Wallis H-Test and Mann-Whitney U Test of demographic groups and geographical domains

Kruskal-Wallis H-test

\begin{tabular}{lccccc}
\hline Dimensions & Age & Profession & Education & Gender & Country \\
Health & 0.754 & $0.012^{\mathrm{a}}$ & 0.163 & 0.137 & 0.872 \\
Environment & 0.940 & 0.388 & 0.201 & 0.623 & 0.677 \\
Mobility & 0.327 & 0.217 & 0.511 & 0.114 & 0.051 \\
Governance & 0.472 & 0.975 & 0.081 & 0.174 & 0.622 \\
Human Capital & 0.653 & 0.399 & 0.303 & 0.241 & 0.358 \\
Social & $0.004^{\mathrm{a}}$ & $0.023^{\mathrm{a}}$ & 0.093 & 0.983 & 0.080 \\
Economy & $0.000^{\mathrm{a}}$ & $0.000^{\mathrm{a}}$ & $0.000^{\mathrm{a}}$ & 0.434 & $0.000^{\mathrm{a}}$ \\
Technology-ICT & $0.000^{\mathrm{a}}$ & $0.000^{\mathrm{a}}$ & $0.018^{\mathrm{a}}$ & 0.076 & $0.000^{\mathrm{a}}$ \\
Culture & $0.037^{\mathrm{a}}$ & 0.195 & 0.610 & 0.148 & 0.583 \\
Smart Living & $0.002^{\mathrm{a}}$ & $0.005^{\mathrm{a}}$ & 0.147 & 0.087 & $0.007^{\mathrm{a}}$ \\
Lifestyle & $0.000^{\mathrm{a}}$ & $0.001^{\mathrm{a}}$ & $0.002^{\mathrm{a}}$ & 0.605 & $0.015^{\mathrm{a}}$ \\
\hline
\end{tabular}

Note : P-value ${ }^{\mathrm{a}}<0.05$ shows a statistically significant difference in those dimensions. Country: developing countries and developed countries

Although non-parametric tests were applied to run the datasets, the disproportional number of respondents between groups would inflate the respondents' rate of the bigger group causing a skewed result. The uneven distribution of sample size found among the categories is unavoidable due to conventional sampling. Reservation of the findings must be noticed and resolved in the application. Therefore, the theory-based scientific study still needs to perform pilot tests locally and consistently in future development.

People's minds are often complicated and evolved along the line of demographic and geographical narrative; therefore, different cause-effect of urbanization engendered by people's underlying motives can be realized by studying the concept of planetary urbanization to the Uqol evaluation reports. The hypothesis is verified with the three objectives fulfilled: First, the Uqol evaluation results indicate the well-being gaps of mobility, economic-socialenvironmental development between the developing and developed countries (rural vs. urban). Second, demographic attributes are illustrated as the independent variables to the dependent geographical factors impacting the evaluation gaps. Third, the demographic groups display significant differences in the social, economy, technology-ICT, smart living, and lifestyle within age, profession, and education categories contributing to most part of the significant differences in the economy, technology-ICT, smart living, and lifestyle between developing and developed countries. 
After comparing and discussing the Uqol evaluation results and the significant differences, the implication to planetary urbanization theory and contribution of the study is presented for exploring the path to bridge the well-being gap identified between the urban (developed countries) and rural areas (developing countries) for revitalizing the postindustrial town and building the resilient sustainable urban-rural society in developing countries.

For a long time, QOL is a subjective term without an agreeable definition among people. Whereas, Uqol evaluation is a specific reflection of the urban condition and can inform future urban development. The study proves that the essence of well-being is health to affirm the human-oriented urban development. The Uqol evaluation results by geography and demography indicate that material well-being based on aspects of GDP per person is not related to the quality of life in a country (Economist Intelligence Unit, 2005; European Commission, 2009; Stiglitz, 2009; Pintér et al., 2012). It implies that the current economicdriven urban development planning strategy needs to address local conditions and demands (DNA), which planetary urbanization advocates, instead of just considering the overgeneralized city-centered and economy-led urbanization strategies. Indeed, urbanization is a socio-economic-spatial process driven by demographic characteristics that directly affect people's ways of life and urban landscape. It precisely suggests that geography is not the determinator of well-being requests but demography. It is slightly different from the hypothesis stated in section 1: introduction. It means that any living location can fulfill the 11 well-being needs (Table 1), people will live there, disregarding urban or rural areas.

In the $21^{\text {st }}$ century, technological advancement facilitates transportation and catalyzes inter-connectivity and inter-exchangeability of people, commodities, information, culture, and political ideology. It formulates the new mix of social and cultural patterns, imposing a new challenge for governance. Often, cultural gaps and conflicts can disturb any establishment and deteriorate the living environment and quality of life. Future urban development needs to address the significant impact triggered by the ICT advancement and its means-end relationship of smart living capable of integrating the urban and remote areas in a holistic system. Therefore, a drastic urban model shift is expected and should be on the way (Raworth, 2018; D'Acci, 2019).

The concept of planetary urbanization proposed by Neil and Schmid initiates a new approach to study urbanization apart from the inherited city-centric sprawling outwards extensively to form the capital-led global urban phenomenon. Planetary urbanization recognized that urbanism is a process driven by human geography, not a form of one location (Arboleda, 2016; Goonewardena, 2018; Schmid, 2018; Wilson et al., 2019). 
Urbanization as a collective endeavor with the multifaceted, politicized, and open platform would be modified according to the constitutively hierarchical multi-dimensional urbanization processes; and the specificity of urbanization as one among a multitude of socio-spatial processes which structure the planetary ways of life today (Brenner, 2018). Thus, understanding the contextual urban problems and neutralizing the rural-urban opposition is necessary for bridging the theoretical and empirical gap (Angelo \& Goh, 2020). The Uqol evaluation results of the demographic and geographical groups conclude that geographical constraints are no longer viewed as significant impediments for future development. Informed by the significant differences of economy, technology-ICT, smart living, and lifestyle. At the same time, the complementary drivers of transit-orienteddevelopment (TOD) and ICT can foster economic growth for merging the well-being gaps between developed countries and developed countries. Furthermore, Büchs\& Koch's (2019) 's Elsevier Atlas award paper supports degrowth in developed nations is needed to preserve the well-being of future generations as an implication of creating a blend of rural and urban lifestyles. Rem Koolhass' "Countryside the Future" exhibition in the Guggenheim Museum of NYC predicts that the future urban development embraces ruralism. Given this, a TOD-ICT-based urban-ruralism (UxR) concept would contribute to healthy living by releasing the economic-social-environmental pressure from the over urbanized city to the rural region, which could be furnished by the high-speed railway network, sharing economy, and ICT advancement.

\section{Conclusion}

The three completed objectives conclude that the hypothesis as 'Uqol evaluation gap is caused by demographic and exhibited geographically for shaping the urban landscape' by recognizing geography's dependent role on the independent demography. When demographic attributes can define urbanization in the digital period, the TOD-ICT-based UxR development path for the developing countries and the developed periphery towns will contribute to the future global urbanization process significantly. The study also reminds us that future urban development must focus not only on economic or materialistic requests but also on the health-mobility-social-environmental-cultural-technological strata. The different urban realities from the developing countries to the developed countries and communities appeal to a transitional human-urban-rural development pathway. On the one side, it can guide the developed countries in revitalizing their outdated urban condition to the 'after a developed period'. On the other side, the TOD-ICT sustainable strategy can enrich and enhance the urban-rural landscape (human, economy, and society) virtually and physically. 


\section{Conflicts of Interest}

The authors declare no conflict of interest.

\section{Acknowledgments}

Thank you to the Politecnico di Torino: Professor Patrizia Lombardi, Dr. Francesca Abastante, Dr. Angioletta Voghera, Dr. Isabella Lami, Dr. Sara Torabi, and Mr. Osman and their Ph.D students for pilot testing the survey forms before bulk distribution. Also, Miss Sara Cravero has been amazingly helpful and generous in translating the English survey into the Italian version. Special thanks go to Mrs. Tecla Zaia (President) and Mr. Sanjay Sankar (Manager) from the Alloggi Ami -NGO to distribute and collect the Mirafiori survey forms.

\section{References}

Ali, H. H., \& Al Nsairat, S. F. (2009).Developing a green building assessment tool for developing countries - Case of Jordan. Building Science, 44(5), 10531064.https://doi.org/10.1016/j.buildenv.2008.07.015.

Angelo, H., \& Goh, K. (2020). Out in Space: Difference and Abstraction in Planetary Urbanization. International Journal of Urban and Regional Research. https://doi.org/10.1111/1468-2427.12911.

Arboleda, M. (2016). Spaces of Extraction, Metropolitan Explosions: Planetary Urbanization and the Commodity Boom in Latin America. International Journal of Urban and Regional Research, 40(1), 96-112. https://doi.org/10.1111/1468-2427.12290.

Brenner, N. (2018). Debating planetary urbanization: For an engaged pluralism. Environment and Planning D - Society and Space, 36(3), 570-590. https://doi.org/10.1177/0263775818757510.

Brenner, N., \& Schmid, C. (2015).Towards a new epistemology of the urban?City (London), 19(2-3), 151-182. https://doi.org/10.1080/13604813.2015.1014712.

Büchs, M., \& Koch, M. (2019). Challenges for the degrowth transition: The debate about wellbeing. Futures, 105(1), 155-165. https://doi.org/10.1016/j.futures.2018.09.002.

Campbell, A. (1976). Subjective measures of well-being. American Psychologist, 31(2), $117-$ 124. https://doi.org/10.1037//0003-066X.31.2.117.

CIMI, (2018), Cities in Motion Index, 2018. Retrieved from https://blog.iese.edu/citieschallenges-and-management/2018/05/23/iese-cities-in-motion-index-2018/.

Club of Rome. (2018). About the club Rome. Retrieved from https://clubofrome.org/aboutus/.

D'Acci, L. (2019). A new type of cities for liveable futures.Isobenefit Urbanism morphogenesis.Journal of Environmental Management, 246(C), 128-140. https://doi.org/10.1016/j.jenvman.2019.05.129. 
Dan Bar-On, A. Caria, M. Tazaki, B. Murphy, H. Herrman, A. Noji, ... Mick Power. (1995). The World Health Organization quality of life assessment (WHOQOL): Position paper from the World Health Organization. Social Science \& Medicine, 41(10), 14031409. https://doi.org/10.1016/0277-9536(95)00112-K.

Diener, E. D. (1995). A value based index for measuring national quality of life. Social Indicators Research, 36(2), 107-127. https://doi.org/10.1007/BF01079721.

Dong, H., Fujita, T., Geng, Y., Dong, L., Ohnishi, S., Sun, L., ...Fujii, M. (2016). A review on eco-city evaluation methods and highlights for integration.Ecological Indicators, 60(1), 1184-1191. https://doi.org/10.1016/j.ecolind.2015.08.044.

Economist Intelligence Unit. (2005). The Economist Intelligence Unit's Quality-of-Life Index, The World in 2005. Retrieved from http://www.economist.com/media/pdf/QUALITY_OF_LIFE.pdf.

European Commission. (2009). Beyond GDP: Measuring progress, True wealth and the wellbeing of nations. Retrieved from https://ec.europa.eu/environment/beyond_gdp/index_en.html.

Gokdemir, O., \& Dumludag, D. (2011). Subjective well-being among ethnic minorities: the Dutch case. Retrieved from https://mpra.ub.uni-muenchen.de/38691/.

Goonewardena, K. (2018). Planetary urbanization and totality.Environment and Planning D Society and Space, 36(3), 456-473.https://doi.org/10.1177/0263775818761890

GPCI. (2018) Global Power City Index 2018. Retrieved from http://mori-mfoundation.or.jp/english/ius2/gpci2/index.shtml.

Kingsford O. E., \& Chan, A. P. C. (2019). Barriers Affecting Effective Application of Anticorruption Measures in Infrastructure Projects: Disparities between Developed and Developing Countries. Journal of Management in Engineering, 35(1), 04018056.https://doi.org/10.1061/(ASCE)ME.1943-5479.0000667.

Land K.C., Michalos A.C., Sirgy M.J. (2012) Prologue: The Development and Evolution of Research on Social Indicators and Quality of Life (QOL). In: Land K., Michalos A., Sirgy M. (eds) Handbook of Social Indicators and Quality of Life Research. Springer, Dordrecht. https://doi.org/10.1007/978-94-007-2421-1_1.

Marans, R. W. (2015). Quality of urban life \& environmental sustainability studies: Future linkage opportunities. Habitat International, 45(P1), 47-52. https://doi.org/10.1016/j.habitatint.2014.06.019.

Marans R.W., \& Kweon BS. (2011) The Quality of Life in Metro Detroit at the Beginning of the Millennium. In: Marans R., Stimson R. (eds) Investigating Quality of Urban Life. Social Indicators Research Series, vol 45. Springer, Dordrecht. https://doi.org/10.1007/978-94-007-1742-8_7.

Marans R.W., \& Stimson R. (2011) An Overview of Quality of Urban Life. In: Marans R., Stimson R. (eds) Investigating Quality of Urban Life. Social Indicators Research Series, vol 45. Springer, Dordrecht. https://doi.org/10.1007/978-94-007-1742-8_1. 
McCrea, R., Shyy, T. K., \& Stimson, R. (2006). What is the strength of the link between objective and subjective indicators of urban quality of life? Applied Research in Quality of Life, 1(1), 79-96. https://doi.org/10.1007/s11482-006-9002-2.

Mikkelsen C., \& Di Nucci J. (2015) Qualitative Methodologies in Geography, Contributions to the Study of Quality of Life. In: Tonon G. (eds) Qualitative Studies in Quality of Life. Social Indicators Research Series, vol 55. Springer, Cham. https://doi.org/10.1007/978-3-319-13779-7_5.

MQCR. (2018). Mercer's QOL city ranking 2018. Retrieved from https://www.mercer.com/newsroom/2018-quality-of-living-survey.html.

Murgaš, F.,\& Klobučník, M. (2018). QualitY of life in the city, quality of urban life or wellbeing in the city: Conceptualization and case study. Ekológia (Bratislava), 37(2), 183-200. https://doi.org/10.2478/eko-2018-0016.

Pintér, L., Hardi, P., Martinuzzi, A., \& Hall, J. (2012). Bellagio STAMP: Principles for sustainability assessment and measurement. Ecological Indicators, 17(1), 20-28. https://doi.org/10.1016/j.ecolind.2011.07.001.

Potter, J., Cantarero, R., \& Wood, H. (2012).The Multi-Dimensional Nature of Predicting Quality of Life.Procedia - Social and Behavioral Sciences, 50(C), 781-790. https://doi.org/10.1016/j.sbspro.2012.08.080

Raworth, K. (2018). Doughnut Economics. Retrieved from https://www.kateraworth.com/doughnut/.

Rezvani, M. R., Mansourian, H., \& Sattari, M. H. (2013). Evaluating Quality of Life in Urban Areas (Case Study: Noorabad City, Iran). Social Indicators Research, 112(1), 203220. https://doi.org/10.1007/s11205-012-0048-2.

Rodriguez D. L. (2015) The Role of Context and Culture in Quality of Life Studies. In: Tonon G. (eds) Qualitative Studies in Quality of Life. Social Indicators Research Series, vol 55. Springer, Cham. https://doi.org/10.1007/978-3-319-13779-7_3.

Schmid, C. (2018). Journeys through planetary urbanization: Decentering perspectives on the urban. Environment and Planning D - Society and Space, 36(3), 591-610. https://doi.org/10.1177/0263775818765476.

SCI (2018). Sustainable Cities Index, 2018. Retrieved from https://www.arcadis.com/en/united-states/our-perspectives/sustainable-cities-index2018/united-states/.

SCMI (2017). Sustainable Cities Mobility Index, 2017. Retrieved from https://www.arcadis.com/en/global/our-perspectives/sustainable-cities-mobility-index$2017 /$.

Shen, L., Lu, W., Peng, Y., \& Jiang, S. (2012). Critical Assessment Indicators for Measuring Benefits of Rural Infrastructure Investment in China.Journal of Infrastructure Systems, 17(4), 176-183. https://doi.org/10.1061/(ASCE)IS.1943-555X.0000066.

SPI (2018). Social Progress Index, 2018. Retrieved from https://www.socialprogress.org/. 
Stiglitz, J. (2009). Towards a better measure of well-being. Retrieved from https://www.ft.com/content/95b492a8-a095-11de-b9ef-00144feabdc0.

Sullivan, G., \& Artino, A. (2013). Analyzing and Interpreting Data From Likert-Type Scales. Journal of Graduate Medical Education, 5(4), 541-542. https://doi.org/10.4300/JGME-5-4-18.

UNFCCC (2016). The Paris Agreement. Retrieved from https://unfccc.int/process-andmeetings/the-paris-agreement/the-paris-agreement.

United Nations. (2020). SDG Moment. Retrieved from https://www.un.org/sustainabledevelopment/sdg-moment/.

Unicef. (2020). Trend of urban population. Retrieved from https://www.unicef.org/sowc2012/urbanmap/.

WCED (1987). Report of the World Commission on Environment and Development: Our common future. Retrieved from https://sustainabledevelopment.un.org/content/documents/5987our-commonfuture.pdf.

Wilson, D., Boodram, B. \& Smith, J. (2019). 2. Public Housing, Heroin Addiction, And America'S Industrial Suburbs: A Planetary Urbanist Perspective. In K. Guney, R. Keil \& M. Ucoglu (Ed.), Massive Suburbanization (pp. 56-78). Toronto: University of Toronto Press. https://doi.org/10.3138/9781487531867-005.

Wilson, D., \& Jonas, A. E. G. (2018). Planetary urbanization: new perspectives on the debate. Urban Geography, $39 \quad$ (10), 1576-1580. https://doi.org/10.1080/02723638.2018.1481603. 